\title{
Mostruário de Práticas: considerações sobre a formação e a atuação de professores dos Anos Iniciais a partir das Feiras Catarinenses de Matemática
}

\author{
A collection of practices: some remarks on teacher's formation and the \\ Mathematical Fairs of Santa Catarina (Brazil)
}

\author{
Viviane Clotilde da Silva \\ Antônio Vicente Marafioti Garnica ${ }^{* *}$
}

\begin{abstract}
Resumo
Esta pesquisa tem por objetivo apresentar e analisar narrativas que, em seu conjunto, permitiram atribuir significado a concepções e práticas atualmente vigentes, relacionadas ao ensino e à aprendizagem de Matemática nos Anos Iniciais, em escolas do estado de Santa Catarina. Ressalta-se, nesse panorama, as Feiras Catarinenses de Matemática. Valendo-se da metodologia conhecida como História Oral, foram coletados, editados e estudados depoimentos de quinze professoras atuantes no início da escolarização formal que têm ou tiveram envolvimento com as Feiras de Matemática, espaço reconhecido na educação catarinense para divulgação de práticas relativas ao ensino de Matemática. As narrativas ressaltam certa lacunaridade na formação inicial dos professores que ensinam Matemática, estratégias possíveis de formação contínua e algumas expectativas quanto ao ensino de Matemática praticado nas Séries Iniciais.
\end{abstract}

Palavras-chave: Educação Matemática. Feiras de Matemática. Santa Catarina-Brasil. Práticas escolares dos Anos Iniciais da Escolaridade Formal. Narrativas.

\begin{abstract}
This research aims to present and analyze narratives that, as a whole, allowed assigning meaning to conceptions and practices related to the teaching and learning of mathematics in the elementary schooling system in the State of Santa Catarina. In this scenario, the Mathematics Fairs of Santa Catarina is noteworthy. Using the methodology known as Oral History, depositions of fifteen active teachers at the beginning of formal schooling were collected, edited and studied, all of them involved with mathematics fairs. Their narratives emphasize aspects of the elementary teachers' formation in Brazil, some possible strategies for their in-service preparation and allows us to understand some of the expectations of these elementary teachers in their daily activities related to Mathematics.
\end{abstract}

Keywords: Mathematics Education. Mathematics Fairs of Santa Catarina-Brazil. Practices. Teachers Formation of Initial Years of Formal Schooling. Narratives.

\footnotetext{
* Doutora em Educação para Ciência pela Universidade Estadual Paulista "Júlio de Mesquita Filho" (UNESP), Bauru/SP. Professora do Departamento de Matemática da Universidade Regional de Blumenau (FURB), de Blumenau/SC. Endereço para correspondência: Rua Maria Campestrini, 45 - ap. 304, Vila Nova, Blumenau/SC, CEP: 89.035-265. E-mail: vivianeclotildesilva @gmail.com.

** Doutor em Educação Matemática pela Universidade Estadual Paulista "Júlio de Mesquita Filho" (UNESP), Rio Claro/SP. Professor do Departamento de Matemática da Universidade Estadual Paulista "Júlio de Mesquita Filho" (UNESP), Bauru/SP e Rio Claro/SP. Endereço para correspondência: Avenida Nações Unidas, 1135/1101, Centro, Bauru/SP, CEP 17010-130. E-mail: vgarnica@fc.unesp.br.
} 


\section{Introdução}

Se é uma distorção qualificar os trabalhos de pesquisa em Educação Matemática meramente a partir de sua aplicabilidade em sala de aula, também seria desastroso afirmar uma desvinculação total entre a pesquisa em Educação Matemática e as práticas que ocorrem na sala de aula de Matemática. Este artigo, surgido de uma tese de doutorado (SILVA, 2014), de algum modo tematiza a aproximação entre a pesquisa acadêmica e as práticas cotidianamente desenvolvidas por professores e estudantes nas escolas de Santa Catarina, focando, mais especificamente, as Feiras Catarinenses de Matemática, atividade já tradicional que envolve a apresentação de experiências de ensino efetivamente desenvolvidas no ambiente escolar que, segundo um conjunto de atores que a este artigo caberá apresentar em momento oportuno, se mostram como diferenciadas no panorama educacional do estado.

A tese de doutorado do qual se originou este artigo trata, além de compreender o movimento de criação e desenvolvimento das Feiras, seus mecanismos, sucessos e entraves, de investigar a formação e a atuação dos professores que participam desses eventos. Durante a elaboração da tese, entretanto, ficou patente a necessidade de registrar, de forma inédita e sistemática, um histórico das Feiras Catarinenses, o que fizemos a partir da mobilização de uma série de fontes documentais escritas e orais. Para o desenvolvimento deste estudo seguimos como guia metodológico os parâmetros da História Oral, temática que, partindo do depoimento de atores considerados significativos para o tema do estudo - no caso, professores participantes das Feiras Catarinenses de Matemática - promove e possibilita a elaboração de uma narrativa coerente e plausível (daí a necessidade de mobilizar fontes de diversas naturezas além das fontes orais) sobre o que um autor pretende compreender.

Para este estudo foram entrevistadas 15 professoras da Educação Básica do estado de Santa Catarina que participaram ativamente das Feiras de Matemática ao longo dos anos em que foram promovidas as trinta edições do evento. Com suas narrativas ${ }^{1}$, elas tentaram ultrapassar o incomunicável que habita todo movimento de comunicação e nos contaram de suas expectativas quanto à carreira, seus envolvimentos com as Feiras, falaram de aspectos de suas formações acadêmicas e de sua atuação como professoras. Do que ouvimos atentamente e registramos cuidadosamente nas textualizações que elaboramos a partir das fontes orais, constituímos sentidos possíveis para o que nos impusemos como tema: compreender, tendo

\footnotetext{
${ }^{1}$ Ainda que, obviamente, as análises deste artigo estejam plasmadas nessas narrativas, tornou-se inviável, por questão técnicas, incluir esses depoimentos ou excertos deles no corpo deste texto. Entretanto, a íntegra dessas narrativas pode ser facilmente acessada em www.ghoem.org.
} 
como espaço as Feiras Catarinenses de Matemática, aspectos da formação e da atuação de professores dos Anos Iniciais da escolaridade. A vinculação entre práticas, experiências, formação, Feiras de Matemática e Ensino Básico pode até parecer um tema fluido, mas é pensando nesse sistema de conceitos, termos e expressões que esta pesquisa se materializou.

Nosso exercício de análise foi, na realidade, um esforço de criar arremates para uma trama de elaborações narrativas, o que fizemos tentando captar o que nos pareceu estar - ora latente, ora explicitamente - nos depoimentos coletados: articulamos recortes discursivos com a intenção de detectar eixos que julgamos significativos a partir do que ouvimos e da busca à documentação complementar sugerida pelos depoimentos ${ }^{2}$. As Feiras de Matemática, por certo, constituem um desses eixos, já que toda a busca às colaboradoras (e boa parte das conversas que com elas mantivemos) teve as Feiras como personagem central. Buscando entender os significados atribuídos às Feiras e o que motiva/motivou nossas depoentes a participar desses eventos, fomos aos poucos elaborando um olhar sobre esses espaços para divulgação de práticas escolares relativas ao ensino de Matemática.

Os outros passos do que, na tese, constituem nossa análise, entram mais especificamente na sala de aula dessas professoras colaboradoras e tentam atribuir sentido às práticas realizadas pelas depoentes no ambiente escolar. Na Educação Inicial - na qual atuam essas professoras -, convém lembrar, não há propriamente uma divisão em disciplinas, ao modo do que ocorre em outros momentos dos Ensinos Fundamental e Médio. Tratar desse nível de ensino, portanto, implica lembrar que as colaboradoras desta pesquisa não necessariamente têm formação em cursos de Licenciatura em Matemática. Elas são o que a literatura atual tem chamado não de professoras de Matemática, mas de professoras que

\footnotetext{
${ }^{2}$ Um dos pareceres emitidos a este artigo aponta necessidade de explicitarmos com mais clareza os aportes teóricos subjacentes ao trabalho, posto que há apenas, no corpo do texto, menções bastante ligeiras sobre análise narrativa (abordagem metodológica que responde a alguns pressupostos teóricos) e breves referências a outros autores e estudos que apoiam nossas análises. A detecção dessas lacunas, entretanto, não foi impedimento para a aprovação deste artigo, mas é importante que nós, autores, atentemos para as recomendações feitas e, para isso, esta nota de rodapé foi acrescentada. Aporte teórico. Com efeito, no artigo estão explicitados alguns autores que nos ajudam a discutir (complementando, reforçando, ou sugerindo possibilidades) alguns elementos surgidos nas tramas de análises. A teorização que sustenta nossa pesquisa, entretanto, segundo a entendemos, é anterior a isso: é o que nos permite chamar esses autores (e não outros) como interlocutores; é o que nos permite chegar à criação das narrativas como chegamos e analisá-las como as analisamos. Assim, análise de narrativas, História Oral, metodologia etc, como mobilizadas neste artigo, são resultados de uma teorização que dificilmente pode ser explicitada, em sua íntegra, no corpo de um único texto. Esforços para compreender o que é, segundo nossa compreensão, uma "teorização" e apontar indícios de quais são nossos fundantes teóricos estão disponíveis em outros textos nossos e de outros autores do GHOEM aos quais remetemos o leitor. Um desses textos é o livro Cartografias Contemporâneas: mapeando a formação de professores de Matemática no Brasil, organizado por Antonio Vicente Marafioti Garnica e publicado em 2012 pela editora Appris. Composto por treze textos elaborados por membros do GHOEM, o livro contém capítulos que debatem, especificamente, o que entendemos por teorização e por fundamentação teórica, bem como capítulos que apresentam trabalhos específicos desenvolvidos a partir de alguns referenciais usuais ao Grupo, exercitando nossas ideias sobre teorização.
} 
ensinam Matemática e, no caso, de professoras que ensinam Matemática e que, nas Feiras Catarinenses, divulgam suas práticas relativas a essa face das suas funções docentes. Isso nos levou a focar, num momento da análise, a formação prévia dessas professoras.

Num momento posterior, entretanto - ou seja, no que se configurou como um terceiro eixo de análise - tentamos investigar as práticas relativas ao ensino de Matemática, isto é, ao modo como, nas salas de aula, são criadas estratégias para tratar conteúdos matemáticos. Nesse caso, aspectos da formação inicial dessas professoras novamente voltaram à cena, haja vista que a presença da Matemática nos cursos de formação é um fator importante nesse contexto em que tentamos compreender como professoras que ensinam Matemática pensam os conteúdos e as estratégias para discuti-los em sala de aula, ou seja, como pensam o ensino desses conteúdos mais específicos ou, ainda, como, efetivamente, ensinam Matemática ou pensam ensinar Matemática. Certamente, voltam também à cena as Feiras, posto que esse lugar praticado se constitui em uma entre as estratégias desenvolvidas por essas professoras para educar matematicamente seus alunos. Isso implica, por fim, que os três eixos de análise Feiras de Matemática, Formação Docente e Práticas de Ensino da Matemática - formem um único bloco, o que torna artificial - mas estratégica, devido à nossa limitação humana de analisar todo o conjunto ao mesmo tempo - a divisão desse bloco em três partes.

No corpo do artigo tentamos promover a inter-relação entre esses três eixos. Iniciamos com uma apresentação - mais descritiva - das Feiras Catarinenses de Matemática, seguida do estudo da formação e das práticas de professores dos Anos Iniciais que participam dessas Feiras. Nessa segunda parte do texto, pensamos, a inter-relação dos eixos torna-se mais evidente.

\section{Para início de conversa: as Feiras e seu funcionamento}

A década de 1960 marcou singularmente a educação no estado de Santa Catarina. Após anos de reivindicações, foi criada oficialmente, em Blumenau ${ }^{3}$, a primeira faculdade fora da capital, Florianópolis: no ano de 1967 criou-se a Faculdade de Filosofia, Ciências e Letras, que integrou a Fundação Universitária de Blumenau (FURB).

Durante o processo de organização da Faculdade de Filosofia, Ciências e Letras [...] inicia-se um movimento em favor da implantação do curso de Matemática. Como principal argumento era usado o fato da ampliação do número de escolas a oferecer o curso ginasial (especialmente após 1960) e, conseqüentemente, uma maior demanda por professores habilitados. Em 27 de maio de 1968 são realizados os

\footnotetext{
${ }^{3}$ Blumenau, cidade situada no Vale do Itajaí, em Santa Catarina, a 129 km de Florianópolis, capital do estado.
} 
exames de habilitação (denominação da época) para os cursos de Biologia, Matemática e Química, nos quais são aprovados 91 dos 122 candidatos. As aulas tiveram início no dia $1^{\circ}$ de junho, em dependências cedidas pelo Colégio Dr. Blumenau, uma instituição privada de ensino. O curso de Matemática - Licenciatura Plena foi reconhecido pelo Decreto $\mathrm{n}^{\mathbf{0}} 71.361$, de 13 de novembro de 1972. (GAERTNER, 2004, p. 199-200)

Durante mais de dez anos, as disciplinas do Curso de Matemática dessa instituição foram ministradas por professores de outras cidades do Brasil (Porto Alegre, Florianópolis e Curitiba), conforme registram Floriani e Zermiani (2009). Apenas em 1982 pode-se considerar formado um corpo docente próprio.

Com a criação do Departamento de Matemática, em 1983, um grupo de professores inicia gestões visando desenvolver atividades de pesquisa e extensão voltadas para a Educação Matemática e Ciências:

Em 1983, por meio da $\mathrm{ACAFE}^{4}$, foi proposto um projeto para formar professores de todo o estado de Santa Catarina na área de Ciências, Biologia, Química, Matemática e Física. Fui convidado para ser o coordenador. Este projeto estava calcado em uma premissa que dizia ser importante dominar o conteúdo, a fim de poder ser um bom professor. Nós não concordamos com isso e, portanto, passamos a uma reformulação, introduzindo, nos cursos, diversas disciplinas que tratassem também da parte didática. Assim, foi introduzida a instrumentação para o ensino da Matemática. Através dela, começou a fabricação de materiais concretos e surgiu daí a noção, a ideia das feiras para toda Santa Catarina. (FLORIANI, 2001, apud ZERMIANI, 2003, p. 39)

Já em 1984, os professores José Valdir Floriani e Vilmar José Zermiani criaram o Laboratório de Matemática da FURB, cuja finalidade era atender à demanda do sistema escolar estadual e municipal por cursos, oficinas e materiais voltados ao ensino de Matemática. Estes professores também desenvolveram projeto de extensão universitária que visava interferir no ensino e na aprendizagem da Matemática por meio da organização de uma Feira de Matemática a ser realizada em parceria com a comunidade. Esse projeto envolveu professores e estudantes do Curso de Matemática da FURB, graduandos já no exercício da docência, seus alunos e os egressos de um curso de Especialização em Ensino de Matemática promovido pela FURB e financiado pelo SPEC/PADCT/CAPES/MEC 5 .

A julgar pela proposta inicial, as Feiras Catarinenses serviriam como um local (um ambiente) em que os professores que desenvolvessem metodologias inovadoras ${ }^{6}$ para o ensino

\footnotetext{
${ }^{4}$ ACAFE: Associação Catarinense das Fundações Educacionais.

${ }^{5}$ SPEC/PADCT/CAPES/MEC: órgão financiador de projetos voltados para Educação e Ciência do Governo Federal (SPEC: Subprograma Educação para a Ciência; PADCT: Programa de Apoio ao Desenvolvimento Científico e Tecnológico; CAPES: Coordenação de Aperfeiçoamento de Pessoal de Nível Superior; MEC: Ministério de Educação).

${ }^{6}$ Metodologias inovadoras, de um modo bastante amplo e pouco tematizado especificamente na documentação consultada, parece ser a expressão usada para se referir a práticas que se diferenciam, de algum modo, da metodologia tradicional de ensino pautada em aulas expositivas com uso de quadro de giz.
} 
da Matemática em suas salas de aula as apresentariam e as discutiriam, incentivando outros professores a procederem dessa forma em suas salas de aula. Segundo Floriani e Zermiani (1985), elas visavam promover estratégias para alteração efetiva no ensino científico de sala de aula. A exposição do trabalho escolar ao público externo transformaria aquele ambiente em verdadeiro laboratório vivo de aprendizagem científica, com a participação da comunidade.

Em 1985, ocorreram, ambas na cidade de Blumenau, a primeira Feira Regional de Matemática, envolvendo trabalhos desenvolvidos nas cidades da região de Blumenau (em julho), e a primeira Feira Estadual de Matemática (em novembro), com trabalhos classificados na região de Blumenau e trazidos de cidades de outras regiões do estado. A ideia, segundo Zermiani (2003), foi fruto de iniciativas inovadoras de egressos do curso de Especialização em Educação e Ciências, então coordenado pelo professor Floriani, bem como de professores e alunos do curso de Matemática da FURB. Ambas tinham como objetivos

\begin{abstract}
Expor material instrucional para o ensino da Matemática; motivar o desenvolvimento de habilidades para a confecção e a manipulação de materiais instrucionais; tornar clara a importância do uso e as limitações do material instrucional; despertar para o ensino integrado na Matemática e desta com outras áreas do saber; promover a divulgação e a popularização dos conhecimentos matemáticos; facilitar o intercâmbio de experiências e conhecimentos. (FLORIANI, J.V; ZERMIANI, V.J. 1985, p. 2)
\end{abstract}

Segundo o depoimento do professor Zermiani, o grande número de objetivos relacionados aos materiais instrucionais se deve ao fato de, na época, década de 1980, haver um movimento favorável ao uso desses materiais. Segundo ele, "estava na moda". Aos poucos, os objetivos foram alterados de acordo com a estrutura do evento, que se modificava com base em discussões entre os envolvidos. Atualmente, as Feiras têm como objetivos, de acordo com o Regimento da XXIX Feira Catarinense (2013):

a) Despertar nos alunos maior interesse na aprendizagem da Matemática; b) Promover o intercâmbio de experiências pedagógicas e contribuir para a inovação de metodologias; c) Transformar a Matemática em ciência construída pelo aluno e mediada pelo professor; d) Despertar para a necessidade da integração vertical e horizontal do ensino da Matemática; e) Promover a divulgação e a popularização dos conhecimentos matemáticos, socializando os resultados das pesquisas nesta área; f) Integrar novos conhecimentos e novas tecnologias de informação e comunicação aos processos de ensino e aprendizagem. (ZERMIANI, 2013, p. 3)

Apesar do pequeno número de trabalhos apresentados (apenas trinta) na I Feira, houve uma repercussão sensível em todo o estado, animando e mobilizando docentes das várias regiões catarinenses. Com o passar dos anos, o evento foi tomando força, de forma que em 2014 realizou-se sua trigésima edição, e na última década, segundo os relatórios oficiais, todas as edições contaram com mais de uma centena de trabalhos (considerada, inclusive, uma limitação imposta pela própria organização devido aos espaços físicos disponíveis). 
Segundo Floriani e Zermiani (1985), as Feiras de Matemática, desde o seu início, deveriam acontecer em duas etapas. Da primeira, a da Feira Regional, participavam trabalhos de vários municípios pertencentes a uma mesma GERED ${ }^{7}$. Na segunda etapa, a Feira Catarinense, propriamente, em âmbito estadual, eram apresentados os trabalhos (sob algum critério tidos como os melhores trabalhos ${ }^{8}$ ) selecionados nas Feiras Regionais.

Em todo o estado de Santa Catarina a única região que sempre realizou Feiras Regionais foi a de Blumenau. No início, em algumas regiões, o número de professores interessados em participar era muito pequeno, não justificando a realização de Feiras Regionais. Naquela época, às regiões que não organizavam Feiras Regionais ficava reservado um número determinado de vagas para a Feira Catarinense, estipulado pela coordenação, e seus trabalhos eram inscritos diretamente na GERED em questão, que fazia a seleção, analisando, quando necessário, o material submetido. Com o passar do tempo, em algumas GEREDs as Feiras passaram a fazer parte do calendário escolar, de forma que o número de professores interessados aumentou, e começaram a ser organizadas mais Feiras Regionais. Hoje, das 36 GEREDs do estado, 16 já organizam Feiras Regionais. Há, inclusive, cidades do estado que promovem Feiras Municipais de Matemática e os trabalhos selecionados nestas Feiras são apresentados nas Feiras Regionais.

Em grande parte das GEREDs, para participar das Feiras Regionais, os professores de cidades em que não há Feiras Municipais enviam a ficha de inscrição com um resumo do trabalho. Todos os trabalhos são aceitos a não ser que o número de inscrições ultrapasse a quantidade possível de trabalhos a serem expostos. Neste caso, uma comissão de professores faz uma seleção com base no material enviado pelo professor.

A divulgação das Feiras sempre foi feita nas escolas e a inscrição de algumas propostas, segundo os depoimentos que coletamos, deve-se principalmente ao estímulo de colegas que julgam diferenciado o trabalho de determinado professor. Isso mostra que o evento, com o tempo, passou a integrar o cotidiano do sistema catarinense de ensino, e algumas dinâmicas próprias, motivadas pelas Feiras e visando às Feiras, foram surgindo. Entre essas dinâmicas, por exemplo, está a rede de comunicação natural, um processo de rede, entre os pares, que usualmente ocorre em qualquer escola e sistema de ensino: um ator do sistema educacional informa/comunica outros sobre a existência das Feiras, convidando-os ou motivando a participação. Há também os professores que se inscrevem nas Feiras por

\footnotetext{
${ }^{7}$ GEREDs: Gerências Regionais de Educação do Estado de Santa Catarina.

${ }^{8}$ O processo de avaliação dos trabalhos será apresentado na sequência deste texto.
} 
vontade própria, por querer mostrar o que desenvolvem em sala de aula, para participar de um espaço em que é possível trocar experiências.

A julgar pelos depoimentos coletados e pela série de relatórios e outros registros escritos gerados pelas comissões organizadoras das Feiras em suas várias edições, um dos princípios que norteiam as Feiras de Matemática é a intenção de incentivar o desenvolvimento de práticas de ensino tidas como diferenciadas e são desenvolvidas, efetivamente, em salas de aula reais, com todos os alunos, em situações cotidianas de ensino. Não se trata de atender a um grupo de expoentes que realizariam, em grupos menores, atividades diferenciadas ou desenvolvidas com a intenção de serem apresentadas nas Feiras. Um segundo princípio, reiterado pelas equipes gestoras, é organizar esses eventos da forma mais clara e participativa possível, congregando todos os participantes que, juntos, decidem sobre as estratégias a serem implementadas. Para isso sempre se realiza, no último dia de cada Feira Catarinense, uma Assembleia Geral, com o intuito de avaliar o evento e sinalizar possíveis e necessárias mudanças. Além destes momentos de discussão, que começaram a se tornar insuficientes, no início da década de 1990 criou-se um fórum específico, com o objetivo de estudar e discutir as Feiras de Matemática e deliberar sobre diversos assuntos: em 1993 realizou-se o primeiro Seminário sobre Feiras de Matemática e, ao todo, já foram realizados cinco Seminários (1993, 2001, 2003, 2009 e 2013) dos quais participaram professores da Educação Básica e Superior e alunos de cursos de Matemática. Nestes eventos, além de minicursos e mesas-redondas, há assembleias nas quais são discutidos assuntos conflitantes e tomadas decisões referentes à organização, à orientação, à avaliação etc.

Importante ressaltar que, devido à abrangência desse evento no estado de Santa Catarina, foi criada, em 2001, durante o II Seminário sobre Feiras de Matemática, uma comissão denominada Comissão Central Organizadora Permanente das Feiras de Matemática que, segundo Zermiani (2002), foi e continua sendo formada pelos representantes das GEREDs, das Secretarias Municipais de Educação dos municípios que realizam Feiras, por professores da Escola Agrotécnica Federal de Rio do Sul - hoje Instituto Federal Catarinense (IFC) - e professores da FURB. A finalidade dessa comissão é assessorar a gestão das Feiras Escolares Municipais, Regionais e Estaduais. Desta forma, a gestão do evento deixou de ser exclusivamente da Universidade Regional de Blumenau e intensificou sua natureza participativa, com a colaboração de representantes de várias entidades educacionais do estado. Ao mesmo tempo em que essa dinâmica de organização vai ficando cada vez mais complexa, ao lado da possibilidade de dinamizar as experiências, mobilizando mais professores, 
envolvendo mais atores, a complexidade pode também atuar no sentido de criar uma trama de controles, prescrições, engessamentos que têm a tendência de conformar as práticas num modelo tido como adequado, dada uma tendência conservadora que insistentemente tem caracterizado a escola. Essa é a natureza própria dos movimentos que vão, cada vez mais, se tornando complexos, e disso devem cuidar as várias comissões que o próprio movimento tratou de criar.

Nota-se, por exemplo, que em decorrência do crescimento das Feiras de Matemática, com o envolvimento das várias regiões do estado nesse projeto, foram criadas normas para seu funcionamento, analisadas e decididas nos Seminários.

Em relação às inscrições, o II Seminário, ocorrido em 2001, deliberou que, a partir daquele ano, só participariam das Feiras Catarinenses trabalhos apresentados e avaliados em Feiras Regionais. Isso se fez necessário, segundo o professor Zermiani (SILVA, 2014), para que todos os trabalhos fossem avaliados pelos mesmos critérios e uma vez que o número de trabalhos deve ser limitado devido ao espaço e aos custos. Desde o início, os trabalhos a serem apresentados nas Feiras devem ser inscritos atendendo a dois quesitos - categoria e modalidade. A categoria indica o grau de ensino do expositor e sempre procurou acompanhar as mudanças ocorridas no sistema educacional, sendo que hoje está dividido da seguinte forma: alunos da Educação Infantil, $1^{\circ}$ ao $5^{\circ}$ anos, $6^{\circ}$ ao $9^{\circ}$ anos, Ensino Médio, Ensino Superior, Professor de qualquer grau de ensino e Comunidade. Os trabalhos inscritos na categoria Professor devem ser fruto de pesquisa do professor em sala de aula e devem ser apresentados por ele. Os da categoria Comunidade ${ }^{9}$ são trabalhos que de algum modo envolvem Matemática, mas que não estão diretamente ligados a atividades de sala de aula.

No III Seminário sobre Feiras de Matemática, realizado em 2006, criou-se a categoria Educação Especial para que nela se inscrevessem professores e alunos que desenvolvem trabalhos relacionados ao ensino da Matemática em "Instituições de Educação Especial, oficialmente reconhecidas" (ZERMIANI, 2009, p. 41). Os trabalhos desenvolvidos com e por alunos com deficiência em escolas de Educação Básica devem ser inscritos segundo o nível de ensino do aluno.

As modalidades, segundo Zermiani (2002), se referem ao tipo de trabalho realizado. Após várias discussões e alterações, em 2001, no II Seminário, de acordo com Zermiani (2002), as modalidades de inscrição ficaram definidas de três formas - Materiais e Jogos

\footnotetext{
${ }^{9}$ Há, além de alunos e professores, membros da comunidade que não mais participam do sistema escolar. Esses também podem se inscrever nas Feiras e, para eles, foi criada a categoria "Comunidade".
} 
Didáticos; Matemática Pura e Matemática Aplicada e/ou Inter-relação com outras disciplinas - e assim permanecem até hoje.

As Feiras Regionais têm a duração de um dia; as Feiras Catarinenses, dois; e o número de autores por trabalho se resume a um professor orientador (dois na modalidade Educação Infantil $^{10}$ ) e dois alunos expositores. Uma limitação que, por sua vez, foi estabelecida, segundo os gestores, devido às limitações orçamentárias e às infraestruturas físicas. Durante o período de apresentação os trabalhos são concomitantemente avaliados por três avaliadores e, no final de cada evento, é anunciado o resultado da avaliação.

A avaliação das Feiras, segundo documentos e depoimentos, sempre foi uma questão bastante discutida: avaliar ou não? Premiar ou não? Se avaliar, como avaliar? Os critérios analisados são justos? Quem os vê como justos? Essas discussões fizeram com que o sistema de avaliação sofresse muitas modificações. Até o ano de 1993 os trabalhos eram avaliados e classificados em ordem decrescente, sendo classificados três em cada categoria, podendo, também, haver menções honrosas. A comissão julgadora era, então, composta por três pessoas (uma delas vinculada à área da Educação e duas à de Matemática), representantes das Secretarias de Educação - estadual e municipal -, professores convidados da FURB e outras instituições de Ensino Superior e professores orientadores que operavam como avaliadores de trabalhos de categorias diferentes das que estavam participando. Na seleção dos professores avaliadores, a comissão organizadora do evento sempre procurou cuidar para que, entre os trabalhos avaliados, não houvesse trabalhos da mesma região do avaliador.

Houve um ano em que se decidiu extinguir a premiação, o que de fato ocorreu na edição de 1987. Ao final dessa III Feira Catarinense, professores orientadores e alunos expositores solicitaram que a avaliação e a premiação retornassem. Verificou-se então que, vilãs ou mocinhas, a avaliação e a premiação eram vistas como necessárias, pois de alguma forma, segundo nossos depoimentos, elas davam respaldo ao trabalho apresentado, operavam como uma forma de reconhecimento e de diferenciação. Trata-se, portanto, de uma diferenciação entre diferenciados, visto que os trabalhos apresentados eram, todos, já préselecionados.

Tentou-se, entretanto, segundo gestores e participantes, "eliminar o caráter de competitividade do evento". No V Seminário sobre Feiras, em 2013, decidiu-se que a avaliação ocorreria da seguinte forma: ao analisar um trabalho, o avaliador recebe a ficha que deve ser preenchida com considerações suas sobre cada um dos critérios de avaliação. Cada

\footnotetext{
10 A quantidade de professores para acompanhar alunos da Educação Infantil se deve ao fato de crianças
} pequenas exigirem maior cuidado. 
avaliador participa de um grupo de, no mínimo, três professores que avaliam, em média, quatro trabalhos. Após a avaliação individual, os avaliadores se reúnem e avaliam cada trabalho com base nos critérios estabelecidos. Isso feito, um professor designado como coordenador de grupo preenche uma ficha ressaltando os pontos positivos do trabalho e apresentando sugestões e considerações gerais. Essa avaliação, segundo as determinações registradas, é enviada ao professor orientador com o objetivo de auxiliar, tanto o professor quanto os alunos, a aprimorar seus estudos. Essa estratégia foi pensada para que os expositores tivessem, como retorno, uma avaliação descritiva e pormenorizada, e não apenas um resultado final, buscando tornar a avaliação mais diagnóstica e processual.

Hoje, os critérios de avaliação são divididos em gerais e (um) específico por modalidade. Os gerais são quatro e avaliam (a) Comunicação (oral e escrita) do trabalho focando-se na clareza, domínio e desenvoltura na apresentação, na adequação da linguagem, na objetividade, na dinâmica, na coerência entre linguagem falada e escrita; (b) Conteúdo Matemático - quesito em que se analisa o domínio do conteúdo matemático dos alunos no desenvolvimento do trabalho, de acordo com a categoria e ano escolar; (c) Qualidade Científica - volta-se à organização e à sistematização do resumo estendido, à metodologia e aos conceitos mobilizados, considerando o ano e a idade dos estudantes; (d) Relevância Científico-Social - em que se observa se o trabalho contribui para a formação de conceitos, de atitudes e de procedimentos. O critério específico diz respeito à ênfase dada ao conteúdo matemático. Nas três modalidades são analisadas a clareza e a objetividade na mobilização das definições e nos conceitos julgados essenciais. Os trabalhos de Matemática Aplicada e/ou Inter-relações são avaliados também quanto à aplicabilidade do modelo matemático e/ou nível de inter-relação proposto. Nos trabalhos inscritos como Matemática Pura são analisadas as operações e propriedades matemáticas utilizadas e naqueles que exploram Materiais ou Jogos Didáticos avalia-se a aplicabilidade desses recursos para o ensino.

Atualmente, a todos os trabalhos, ao final das Feiras, são atribuídos títulos de Destaque ou Menção Honrosa (decidiu-se que 75\% dos trabalhos receberão a premiação de Destaque, e os $25 \%$ restantes, tidos como aqueles que podem ser ainda melhor explorados, recebem Menção Honrosa). Todos os grupos recebem um troféu de mesmo modelo (os diferencia a classificação) e os alunos recebem medalhas. Essa parece ter sido a forma encontrada para minimizar a característica de competição e da diferenciação extremada que os professores e estudantes, aparentemente, desejariam manter. Ao fim e ao cabo, a 
diferenciação ostensiva, em meio a tantas alterações nos critérios, torna-se mais tênue - mas ainda existe, claramente e certamente - com as regras em vigor.

\section{Ampliando a conversa: os participantes das feiras (depoentes desta pesquisa), suas formações e práticas}

Saber quem são os participantes das Feiras e, particularmente, quem foram nossas depoentes é um ingrediente substantivo para compreender o evento e seu entorno. A este tema dedicamos os tópicos a seguir.

Ao pensar nas estratégias que mobilizaríamos para desenvolver o trabalho do qual resultou este artigo, uma de nossas primeiras questões, já tendo situado nosso tema e nossa opção metodológica pela História Oral, foi sobre quem seriam nossos colaboradores. Pensamos em focar - por interessar a outros projetos que vínhamos desenvolvendo professores ${ }^{11}$ dos Anos Iniciais da escolaridade formal, que participaram como orientadores de trabalhos apresentados em edições da Feira Catarinense de Matemática. Para chegarmos a nomes de possíveis colaboradores analisamos todos os Relatórios e Anais disponíveis ${ }^{12}$ das vinte e cinco primeiras Feiras Catarinenses de Matemática, de 1985 a $2009^{13}$. Muitos desses registros, entretanto, tiveram que ser descartados por não apresentarem o nome dos professores orientadores dos trabalhos apresentados. Verificou-se, no estudo dessa documentação inicialmente mobilizada, a frequência com que cada professor dos Anos Iniciais de escolaridade - junto de seus alunos - foi selecionado para apresentar trabalhos. Disso, foram chamados a colaborar professores com maior número de participações e alguns dos que participaram das primeiras edições da Feira.

A busca concentrou-se, mais particularmente, em professores que apresentaram trabalhos em mais de uma das Feiras Catarinenses de Matemática por acreditarmos que a frequência de participação cuidaria de, ela mesma, indicar professores insistentes em tornar públicas e compartilhar - não apenas circunstancial, informal ou ocasionalmente - suas práticas de sala de aula, mais propriamente as práticas que eles próprios julgavam, segundo algum critério, diferenciadas, boas, interessantes. Isso não implica, entretanto e obviamente,

\footnotetext{
11 Até esse momento não sabíamos que contaríamos apenas com depoentes professoras. Portanto, ainda usávamos o genérico no masculino: "professores".

${ }^{12}$ No início, não havia Anais das Feiras (começaram a ser confeccionados a partir de 1999), e muitos relatórios se perderam.

13 As Feiras de Matemática continuam sendo realizadas. Nossa coleta teve 2009 como ponto final, posto ter sido este o ano em que iniciamos nosso trabalho.
} 
que professores com poucas participações ou professores mais recentemente incluídos no rol de participantes não possam ter experiências significativas a relatar ou que suas concepções e práticas não estejam em nosso horizonte de preocupação. Ocorre que é preciso, para um trabalho de pesquisa, fazer opções para torná-lo exequível e esse foi, portanto, o caminho que tomamos. Estudos posteriores e complementares podem ter como colaboradores outros professores participantes (ou até mesmo, por exemplo, os que optam por não participar das Feiras ou foram delas excluídos pelos critérios de seleção de cada instituição), com os quais panoramas cada vez mais amplos poderão, aos poucos, ser esboçados. Selecionados os professores, procedemos a uma análise inicial, temporal e geográfica, verificando a região onde eles se encontravam e de quais Feiras haviam participado. A partir dessa análise, selecionamos dezenove professoras que haviam participado de três ou mais edições das Feiras Catarinenses e quinze delas - residentes em 10 diferentes municípios catarinenses - aceitaram colaborar com a pesquisa e efetivamente colaboraram.

Ao conversar com nossas depoentes sobre as Feiras, vieram à cena temas como a precariedade da formação; o movimento de aproximação delas com a Matemática e como essa aproximação reverberava em suas práticas docentes nos Anos Iniciais; as Escolas Multisseriadas; os métodos de ensino específicos mobilizados para salas de aula diferenciadas daquelas do sistema usual de escolarização; e as Escolas do Campo, afastadas das cidades e voltadas para atender à comunidade campesina.

Um ponto que chamou nossa atenção nas narrativas foi que nossas colaboradoras, mesmo tendo começado seus estudos nas décadas de 1960 e 1970, iniciaram o Magistério atuando em classes multisseriadas, algumas delas tendo, também, frequentado escolas assim como alunas. Uma delas, inclusive, ainda atua em escola multisseriada, em espaço escolar aparentado com aqueles do sistema campesino do passado. A realidade das escolas dos níveis iniciais de ensino do estado de Santa Catarina inclui, ainda, um grande número de escolas no campo, o que torna necessário e muito atual o debate sobre a educação campesina catarinense, havendo, inclusive, cursos universitários específicos para essa discussão. Diferentes das Escolas Rurais usuais, como as estudadas por Martins (2003), por exemplo, nas quais eram oferecidas apenas as três Séries Iniciais, sendo que a quarta série e os estudos posteriores deveriam ser feitos em unidade escolar urbana, todas as Escolas Multisseriadas nas quais atuaram ou estudaram as nossas depoentes operavam com as quatro séries.

Essas escolas geralmente possuíam uma infraestrutura básica adequada (se comparada às escolas campesinas do passado) com sala, cozinha e banheiro. O professor, entretanto, 
exatamente como no passado, além de assumir, nessas escolas, seu papel profissional específico, tinha que cuidar da merenda (quando havia), da limpeza e da burocracia escolar. A precariedade das Escolas do Campo devia-se ao fato de, até a metade do século XX, para o Governo Federal, o meio rural se caracterizar pelo latifúndio e pela monocultura, não necessitando de educação, nem mesmo de alfabetização. Maior preocupação dos órgãos governamentais ocorreu apenas a partir da década de 1990, quando a educação campesina passou a ser vista como uma questão de interesse nacional, tendo, então, a Constituição de 1988, segundo as Diretrizes Operacionais para Educação Básica nas Escolas do Campo (BRASIL, 2001), induzido, na LDB, o tratamento dessa modalidade educacional no âmbito do direito à igualdade e do respeito às diferenças. Mesmo apresentando estruturas físicas semelhantes, as escolas campesinas catarinenses possuíam um sistema diferenciado de ensino. Havia, por exemplo, escolas nas quais a multisseriação não ocorria com as quatro séries, mas em salas que comportavam crianças de duas séries distintas, apenas, mas nem sempre ocupavam o mesmo espaço séries sequenciais.

Muitas depoentes ressaltaram as dificuldades enfrentadas para chegar à escola, exatamente como nos relatos de outras regiões e relativos à outra época, por exemplo, aqueles apresentados por Martins (2003). Em algumas situações, era necessário utilizar vários meios de transporte (ônibus ou bicicleta ou ir a pé) para chegar à escola todos os dias; em outras, nem sempre havia transporte, o que obrigava a professora a dormir em casa de alguma família durante a semana. De acordo com as depoentes, a experiência nessas escolas, como alunas, foi positiva, o que nos permite afirmar que essa vivência talvez tenha tornado mais suave a passagem de alunas a professoras de escolas dessa mesma natureza. A dedicação do professor e o companheirismo dos colegas fizeram com que elas, em suas narrativas, se lembrassem dessas situações com certa ternura, segundo a perspectiva da entrevistadora. As marcas positivas se devem, principalmente, ao apoio da comunidade e ao que lembram como sendo um espírito de cooperação entre os alunos. Como as turmas eram pequenas e envolviam estudantes de vários níveis de aprendizagem, havia a possibilidade de os mais adiantados orientarem os mais novos, como que numa reedição do Método Lancaster, o que (embora possa desagradar à literatura que defende a ultrapassagem desse método por abordagens posteriores) era, segundo as depoentes, algo bastante positivo, pois contribuía para a união e o convívio harmonioso das turmas. As dificuldades encontradas por essas professoras, principalmente na questão de locomoção, entretanto, faziam com que procurassem mudar de escola assim que possível, ou seja, no momento em que houvesse vagas em escola mais 
próxima às suas residências. Essa situação é similar ao que foi detectado por MartinsSalandim (2012, p. 137) e que permite a essa autora afirmar que as professoras "permaneciam por pouco tempo em cada escola, buscando sempre por escolas de mais fácil acesso e urbanas, o que tornava as escolas da zona rural uma 'terra de passagem"'.

No que diz respeito à cultura matemática escolar dos professores que atuam nos Anos Iniciais da escolarização - grupo do qual fazem parte as professoras colaboradoras desta nossa pesquisa - é possível afirmar que a configuração das instâncias formadoras, nesse aspecto, pouco se alterou com o passar dos anos. As Escolas em que foram formadas as nossas depoentes, via-de-regra, secundarizavam a importância da Matemática em seus programas. Com a promulgação da Lei 5.692/71, o Curso Normal passou a ter apenas a disciplina Didática da Matemática no $3^{\circ}$ ano, o que diminuiu ainda mais o estudo de disciplinas específicas. Além de haver uma carga horária insuficiente para o ensino da disciplina, muitos cursos ainda sofriam com a falta de professor habilitado para lecioná-la.

Como afirmam Nacarato, Mengali e Passos (2009, p. 17), referindo-se às Propostas Curriculares estaduais elaboradas na década de 1980, "se por um lado, alguns desses cursos tinham uma proposta pedagógica bastante interessante, por outro, na maioria deles não havia educadores matemáticos que trabalhassem com as disciplinas voltadas à metodologia de ensino de matemática". Isso implicava que os tópicos relativos à Matemática fossem ensinados por pedagogos, que os desenvolviam baseados apenas em metodologias apartadas de um conhecimento mais aprofundado dos objetos matemáticos - por mais elementares que fossem - ou, ainda, por pessoas sem formação específica, que assumiam a disciplina e, muitas vezes, a ensinavam sem qualquer relação com as questões voltadas ao ensino e à aprendizagem.

Os depoimentos das professoras que colaboraram com esta pesquisa e que cursaram o Magistério podem ser, no que diz respeito a essa temática, dividido em dois blocos: o daquelas que tiveram professores que ensinavam a matéria tentando estabelecer conexões com o ensino, e o daquelas cujos professores, mesmo trabalhando em um curso preparatório para a docência, lecionavam a Matemática usual do $2^{\circ}$ Grau. As narrativas que compõem o primeiro bloco ressaltam que, mesmo tendo dificuldade em trabalhar com temas de Matemática, a experiência de formação com professores que enfatizavam aspectos do conteúdo junto às questões próprias do ensino foi bastante positiva, permitindo que as depoentes começassem a entender Matemática e a gostar dessa disciplina quando confeccionando materiais de apoio didático e explorando o uso de material concreto. Para as professoras que já tinham facilidade 
em Matemática e "gosto pela disciplina", a experiência com esse tipo de aula foi ainda mais motivadora. Para nossas depoentes, até onde pudemos perceber, a atuação do professor que participou de suas formações, nessa etapa do ensino, foi essencial para que pudessem começar a mudar a sua visão no que se refere à Matemática.

O ensino de métodos, aliado aos materiais e ao conhecimento matemático envolvido, "o porquê da Matemática, onde se aplica”, conforme mencionou uma das depoentes, formam a base do conhecimento que um professor que ensina Matemática deve ter. Há, ainda, relatos - e esses integram o segundo bloco ao qual nos referimos anteriormente - sobre professores que, tendo formação matemática, não trabalhavam com as questões próprias à formação de futuros docentes e de profissionais de outras áreas que, embora tivessem algum conhecimento matemático, não aliavam conteúdo e formas de tratamento a esse conteúdo de um modo que seria desejável à formação no Magistério. Nesse segundo bloco estão os depoimentos de professoras que integram o grande grupo de alunos que passam/passaram pela formação à docência sem manter relação alguma com o conhecimento mais aprofundado da Matemática que deveriam ensinar nem com os vários métodos para o seu ensino.

Em muitas universidades, o Curso de Pedagogia, no qual ocorre a formação da maioria dos professores que atua nas Séries Iniciais da escolaridade, promove uma formação generalista, de forma que o ensino de Matemática se restringe a um ou dois semestres, o que não é julgado suficiente para preparar o futuro professor, devido à quantidade e diversidade de conteúdos e metodologias que devem (ou podem) ser explorados. Em pesquisa realizada em instituições de Ensino Superior, Curi (2005) verificou que há predomínio dos métodos e procedimentos em detrimento do estudo do conteúdo. A autora complementa afirmando que, como consequência desse estado de coisas, muitos dos futuros professores concluem o curso sem conhecer os conteúdos matemáticos com que trabalharão. "Parece haver uma concepção dominante de que o professor polivalente não precisa 'saber Matemática' e que basta saber como ensiná-la" (CURI, 2005, p. 70).

Em Santa Catarina, verificamos que ocorre o mesmo que no Brasil como um todo. Segundo o site e-MEC, das Instituições de Educação Superior e Cursos Cadastrados no Ministério da Educação (MEC), 51 instituições de Ensino Superior oferecem o Curso de Pedagogia. Dessas, 16 oferecem essa graduação somente na modalidade de ensino a distância, 31 são desenvolvidas presencialmente e 04 dispõem do curso nas duas formas de ensino (presencial e a distância). Analisamos as grades dos cursos disponibilizadas no site ${ }^{14} \mathrm{e}$

\footnotetext{
${ }^{14}$ Dos 51 cursos em funcionamento, 46 (30 presenciais e 16 a distância) têm seus sites disponíveis.
} 
verificamos que, tanto na modalidade presencial quanto na modalidade a distância, cerca de $65 \%$ dos cursos oferece somente uma disciplina explorando fundamentos e metodologia do ensino de Matemática. Apesar das inúmeras mudanças no decorrer dos anos, os cursos de formação dos professores das Séries Iniciais ainda enfrentam sérios problemas em relação ao ensino de Matemática, dadas a amplitude de seus programas e a generalidade que caracteriza suas propostas. O fato de haver poucos momentos específicos para tratar de conteúdos e abordagens do ensino de Matemática implica uma séria deficiência para os professores em seus cotidianos como docentes.

Entre nossas depoentes, apenas duas cursaram Licenciatura em Matemática. As demais têm formação em Pedagogia. Dessas, a grande maioria faz críticas relacionadas à presença da Matemática em seus programas de graduação: algumas não tiveram aulas de Matemática e as que tiveram relataram que foram insuficientes para que aprofundassem seus conhecimentos e ultrapassassem suas dificuldades quanto a esses conteúdos. Grande parte das professoras fez seu curso superior entre os anos de 1969 e 1996, período em que vigorava Lei $\mathrm{n}^{\mathrm{o}}$ 5.540, sancionada em 28 de novembro de 1968, que permitia ao licenciando do Curso de Pedagogia optar entre várias habilitações disponíveis: Supervisão Escolar, Orientação Escolar e Inspeção Escolar, bem como a habilitação para lecionar no Curso Normal. Essas especialidades não tinham como objetivo final formar professores para atuar em sala de aula (apesar de darem aos licenciandos essa possibilidade) e, por esse motivo, concentravam-se em disciplinas específicas relativas à habilitação, não fazendo parte de sua grade de disciplinas qualquer curso, de natureza pedagógica, voltado à Matemática. Desse modo, muitos professores, como é o caso de algumas de nossas entrevistadas, foram para a sala de aula sem formação específica alguma para o ensino dessa disciplina. Esse fato pode ter sido, por um lado, um problema para muitos docentes que não tinham o conhecimento necessário para lecionar e, por outro, para muitos alunos que, diante de professores mal preparados, corriam o risco de aprender conceitos equivocados.

Tão sério quanto o fato de os cursos não oferecerem disciplinas relacionadas à Matemática escolar é o oferecimento da disciplina para meramente cumprir uma formalidade, sem desenvolver seus tópicos de forma minimamente adequada com vistas a preparar o futuro professor. Algumas das professoras colaboradoras deste trabalho viveram situações dessa natureza e relatam não terem levado, dos seus cursos de graduação, experiência significativa ou alguma experiência - em relação à Matemática. Uma das professoras lembrou que cursou a disciplina Matemática, mas que não tinha disso muitas lembranças. Outras, em suas 
narrativas, descrevem com detalhes a disciplina Estatística e sequer mencionam se tiveram ou não outra disciplina relacionada à Matemática. A Estatística, por sua vez, foi ressaltada em dois depoimentos por motivos opostos. Em um, a professora fala das dificuldades que teve na disciplina e, no outro, a colaboradora relata que foi cursando essa disciplina que conseguiu superar seus medos e traumas em relação à Matemática, tornando-se uma excelente aluna.

Vários depoimentos também nos mostraram cursos superiores que auxiliaram na formação matemática das professoras. Muitas delas narraram sua formação e declararam que essa etapa do ensino contribuiu para mudar sua relação com a Matemática e suas práticas de sala de aula. Aparentemente, a Matemática na Educação Básica foi traumática para muitas delas, pois as únicas recordações são experiências com um trabalho, digamos, mais prático, envolvendo métodos e procedimentos para tratar conteúdos bastante elementares. Essas marcas negativas do processo de ensino e aprendizagem na Educação Básica, podem, como afirmam Nacarato, Mengali e Passos (2009), gerar "bloqueios para aprender e para ensinar" (p. 23). Por outro lado, também podem criar o efeito reverso, isto é, levar o professor a procurar formas de fazer com que a sua atuação não seja uma reprodução dos exemplos que teve, para que seus alunos não enfrentem os mesmos problemas que ele. Dentre nossas depoentes, várias das que não trazem boas recordações da aprendizagem da Matemática na Educação Básica afirmam que os problemas enfrentados por elas, enquanto alunas, as fizeram buscar metodologias diferenciadas para que os seus alunos não tivessem a mesma experiência desastrosa que tiveram.

Uma solução encontrada por muitos dos professores que registram, em seus depoimentos, dificuldades em relação à Matemática, foi a de buscar, por iniciativa própria, cursos ou estratégias de formação continuada em programas de pós-graduação ou, mesmo, de formar grupos informais, que atuam/atuaram, apartados ou em rede, para suprir suas deficiências, permitindo-lhes desenvolver seu trabalho da melhor forma possível. Talvez a participação nas Feiras Catarinenses também opere nesse sentido, ainda que não tenha havido menção explícita a isso nos depoimentos. A maioria de nossas depoentes cursou alguma especialização na sua área de atuação, mas muitas dessas apenas mencionaram esse momento da formação, não salientando sua importância (ou não) para seu desenvolvimento profissional. Acreditamos que, além de poder ter como objetivo um conhecimento mais aprofundado e 
amplo, a perspectiva de avanço na carreira - com o consequente aumento salarial - também pode ter servido de potente motivador para a realização desses cursos ${ }^{15}$.

Além de cursos de complementação/especialização, as depoentes afirmam sempre terem buscado, por iniciativa própria, desde o início de suas carreiras, novas metodologias, maiores conhecimentos, ou seja, tudo o que pudesse auxiliá-las na prática de sala de aula, uma vez que muitas declararam ter "medo", "pavor" de Matemática, e que, enquanto alunas, trabalhavam tecnicamente, uma vez que pouco entendiam daquilo tudo (que, futuramente, deveriam ensinar). Como estratégias de superação, pesquisavam, em livros didáticos e paradidáticos, alternativas diferenciadas para ensinar determinado conteúdo, materiais didáticos que facilitassem o entendimento dos alunos e experiências bem-sucedidas de professores mais experientes e faziam cursos relacionados à Educação Matemática.

A dedicação de muitos professores - nisso incluídas as professoras que colaboraram com este nosso trabalho - parece gerar, ao menos em suas comunidades locais e/ou regionais, certo reconhecimento ou destaque. Esse destaque se dá por meio do desempenho de seus alunos, do reconhecimento dos pais e da comunidade ou pelo modo como alguns esforços circulam em espaços públicos, como as exposições ou Feiras de Ciências e/ou Matemática. A importância dessas iniciativas sempre vem à cena quando conversamos com alunos e administradores escolares, ainda que nem todo destaque a um ou a outro profissional, a uma ou a outra prática, possa ser creditado à iniciativa unicamente do professor que busca se engajar em estratégias de formação continuada.

Esta pesquisa tem, nesses professores (no nosso caso, professoras), seu centro de interesse. São professoras que, apesar da formação deficitária (principalmente no que diz respeito à Matemática), transformaram suas salas de aula em ambientes nos quais criaram práticas, alternativas ou não, mas suficientemente satisfatórias (segundo os critérios de certa comunidade), de modo a serem tornadas públicas, em eventos locais, regionais e/ou estaduais de divulgação de estratégias diferenciadas de ensino de Matemática.

A partir dos depoimentos por nós coletados é também possível considerarmos a atuação de nossas depoentes a partir do que elas próprias nos dizem dessa atuação, a partir do que elas nos contam sobre suas práticas. Concentrar-nos-emos, então, nas práticas narradas,

\footnotetext{
${ }^{15}$ Analisamos os Planos de Carreira do Magistério dos municípios onde atuam as colaboradoras, assim como o Plano de Carreira do estado de Santa Catarina, uma vez que algumas trabalham/trabalhavam na Rede Estadual de Ensino. Apesar de não ter acesso aos planos de carreira mais antigos, analisamos os atuais (quase todos elaborados após o ano de 2000). Verificamos que todos oferecem vantagens salariais vinculadas a cursos complementares, sejam os chamados cursos de aprimoramento vertical (pós-graduação, mestrado e/ou doutorado) ou horizontal (cursos afins desenvolvidos ao longo da carreira).
} 
buscando detectar resíduos de possíveis concepções, em relação à Matemática e ao seu ensino, que sustentam essas práticas e, de um modo ou outro, são por elas manifestadas.

Percebemos, nos depoimentos das professoras, uma forte tendência para o uso do material didático concreto. Todas concordam que a manipulação de materiais ajuda na aprendizagem do aluno dos Anos Iniciais, auxiliando-o a compreender os processos e conceitos. A ideia dessas professoras converge para a afirmação de Passos e Romanatto (2010, p. 33) de que "o processo de aprendizagem de uma ideia matemática mostra que essa aprendizagem deve evoluir a partir de um envolvimento ativo com objetos concretos (reais ou imagináveis) até as análises, as sínteses, as sistematizações, as generalizações, as abstrações e as formalizações".

Ao buscar entender qual a concepção de concreto dessas professoras, percebemos que a maioria mobiliza o termo para se referir a materiais didáticos (Quadro de Pregas, Ábacos, Material Dourado, Blocos Lógicos, jogos etc.) e objetos de manipulação (pedrinhas, palitos de picolé, tampinhas, grãos, sucata etc.), pensando ambos como estratégias que podem ser fisicamente operacionalizadas para que a criança compreenda conceitos, seguindo bem de perto a linha construtivista piagetiana (ou uma versão popular, bastante divulgada, desse construtivismo). Outras procuram associar esses materiais a objetos encontrados no dia a dia do aluno, que tenham para ele um significado real, ou seja, não são meros objetos de manipulação, mas estão relacionados com o que está sendo ensinado. Entre os exemplos, aparecem estratégias para o ensino das unidades de medida e os folhetos de propaganda de produtos e promoções de lojas para trabalhar operações.

Trabalhar simultaneamente o material concreto e o que elas próprias chamam de “contextualização" e/ou "interdisciplinaridade” foi o que outras depoentes afirmaram fazer ao narrarem suas práticas. Esse tipo de atividade vai ao encontro do que os Parâmetros Curriculares Nacionais (PCNs) de Matemática (BRASIL, 1997, p. 29) apresentam sobre a relação que o aluno deve estabelecer com o saber matemático, ou seja, "O significado da atividade matemática para o aluno também resulta das conexões que ele estabelece entre ela e as demais disciplinas, entre ela e seu cotidiano e das conexões que ele percebe entre os diferentes temas matemáticos". Nossa experiência como formadores de formadores tem mostrado que o desenvolvimento de trabalhos desse tipo tem sido muito incentivado pelas Secretarias de Educação, estando explícito esse incentivo, inclusive, em muitas das formulações e reformulações de políticas públicas voltadas à Educação, como é o caso das Propostas Curriculares. 
Nos depoimentos apresentados, podemos perceber que, quando falam em interdisciplinaridade, as professoras declaram que os trabalhos/projetos desenvolvidos com a disposição de implementá-la envolvem as várias disciplinas de forma que elas se complementam nas atividades dos alunos. Dizem nossas depoentes: "Tem Matemática na Geografia, Matemática na História [...], tudo envolve [Matemática]. Teve uma época em que eu não chegava a falar em Matemática pra eles, mas os cálculos estavam todos ali, todo conteúdo, tudo, tudo ali dentro”; "[...] eu trabalho sempre, com todas as turmas, é a interdisciplinaridade. Eu não consigo trabalhar as coisas soltas. [...] eu vou buscar, dentro da Ciência, da Geografia, da História, o que eu estou trabalhando, ou dentro da realidade deles, o que eles estão vivenciando naquele momento"; "Uma aula interessante não era só a Matemática, eram as outras disciplinas também e de repente entrava na Matemática porque tem que entrar numa disciplina sem que as crianças percebam”.

Em várias partes de suas narrativas, as professoras descrevem como os alunos se envolveram nas atividades, mostrando que eles questionavam, pesquisavam, construíam e resolviam os problemas que surgiam durante todo o processo de aprendizagem. Para essas professoras, o estudo da Matemática relacionado a aplicações, dando um sentido a ele e relacionando-o com outras disciplinas, é a forma de se trabalhar interdisciplinarmente em sala de aula. A Resolução de Problemas também é uma tendência na Educação Matemática que, segundo as depoentes, tem sido explorada trazendo excelentes resultados, uma vez que " $f a z o$ aluno pensar". O trabalho dessas professoras - esse é o discurso que defendem de modo muito claro - busca fazer com que os alunos criem estratégias para resolver problemas e que, como resultado, se tornem críticos, criativos e questionadores. Seguem, portanto, as nossas depoentes, segundo seus discursos, tendências enunciadas claramente nas diretrizes educacionais em vigência.

Outra estratégia de ensino também muito utilizada por essas professoras, segundo os depoimentos, são os projetos. Algumas começaram a desenvolvê-los logo no início de suas práticas, e outras quando tiveram contato com as Feiras de Matemática, já que este é um evento que incentiva especificamente práticas dessa natureza. Nos recortes dos depoimentos apresentados notamos que os projetos desenvolvidos pelas professoras junto aos seus alunos, em sua maioria, envolviam assuntos que, segundo elas, eram de interesse da turma ou da professora (que "mostrava" aos alunos a importância do tema). No nosso entender, trabalhos desse tipo, que exploram temas que fazem parte do centro de interesse dos alunos ou situações 
relacionadas à realidade tendem a motivar os educandos e fazê-los se envolver no estudo, uma vez que eles se veem incluídos em certas práticas, fazendo parte de certo contexto.

Os projetos, segundo os depoimentos, não são pontuais, desenvolvidos em um curto espaço de tempo, mas têm a duração de alguns meses ou, até mesmo, de um ano letivo, explorando conceitos que deveriam ser estudados numa determinada série em várias disciplinas. Em alguns depoimentos, as Feiras de Matemática aparecem como elemento motivador (mesmo que de forma indireta) para que algumas professoras começassem a trabalhar com esses projetos (ou com aquilo que chamam, como o fazem também alguns autores, de metodologia de projetos). Contudo, o fato de elas verificarem que esse tipo de atividade leva os alunos a se interessarem pelos estudos as motivou a continuar a trabalhar dessa forma, mesmo quando não mais participando do evento. Vinculadas a essa perspectiva, estão também as críticas sobre uma artificialização que, segundo as depoentes, tem ocorrido sem que as equipes gestoras das Feiras consigam controlar: há professores que preparam alunos apenas com a intenção de participar das Feiras, uma crítica usual nos depoimentos que tivemos à mão.

Nas narrativas das professoras, verificamos que as estratégias de ensino por elas desenvolvidas são bastante diversificadas, convergindo, porém, para um ponto comum. Todas enfatizam, em seus depoimentos, uma busca por trazer, para o dia a dia da sala de aula, a realidade em que o aluno vive. Utilizam folders, passeios de estudos, visitas a mercados e bancos, fazem simulações de situações reais em sala de aula, além de utilizar materiais concretos e jogos e realizar estudos sobre temas que envolvem os alunos ou pelos quais eles se interessam. As narrativas tendem a afirmar que isso implica uma metodologia diferenciada e inovadora.

Essa ênfase em aproximar o ensino das situações reais em que vivem os aprendizes não é nova, mas é sim bastante presente no ideário educacional e se manifesta claramente nas políticas públicas atuais. Em vários momentos da educação nacional, percebemos diretrizes que indicam ao professor a necessidade de contextualizar, trazer a realidade do aluno para a escola, defendendo a importância de realizar projetos. Um dos ideários mais significativos e duradouros no quadro dessas propostas foi, sem dúvida, o da Escola Nova.

As práticas relatadas são desenvolvidas com base em como essas professoras acreditam que a aprendizagem das crianças ocorre, ou seja, são retratos que nos permitem perceber aspectos das concepções que cada uma defende e usa como guia para suas práticas cotidianas, sejam efetivas ou desejadas essas práticas. Não se trata, aqui, de evidenciar se as 
práticas relatadas são ou não realmente as práticas realizadas ou se o discurso tem sincronia com o que ocorre no cotidiano das escolas em que as depoentes atuam. Trata-se de, a partir do que afirmam, entender o que e como elas elaboram suas práticas para, então, narrá-las, e de como, nessas narrativas, defendem certas diretrizes, concepções, modos de ver e modos de lidar considerados adequados e, até mesmo, ideais.

Os depoimentos das professoras permitem afirmar que seus discursos têm sincronia com o que atualmente tem sido defendido e proposto nas searas das políticas públicas ou no campo da pesquisa em Educação Matemática. As justificativas e as considerações fundamentam-se em perspectivas mais gerais, mais disseminadas e associadas aos documentos oficiais que transitam pelas escolas.

Segundo Nacarato, Mengali e Passos (2009), a visão que o professor tem da Matemática fundamenta a sua prática. Dessa forma, aquele que tem a visão utilitária da Matemática, que a vê como uma ferramenta, tende a trabalhar enfatizando regras e procedimentos. Não é isso, entretanto, que os depoimentos das professoras nos permitem perceber: ao mesmo tempo em que mobilizam o discurso da utilidade da Matemática, de que a Matemática “está em tudo”, elas narram esforços para dar sentido à Matemática que, em meio a tantas dificuldades, ensinam, tentando fugir de regras e procedimentos visando a um significado que transforme o aluno e a sala de aula. São traços de um discurso, portanto, que alia técnica, utilidade e aplicação, num horizonte que propõe - ao menos discursivamente intervenções significativas.

\section{Para finalizar}

Tentar captar concepções de professores sobre o ensino e a aprendizagem de Matemática - ou qualquer concepção que seja, de quem quer que seja - é um projeto fugidio, tênue, não objetivo. É impossível, ao final de um movimento de pesquisa, por mais aprofundado que seja e por mais que o pesquisador tenha se comprometido com ele, dizer $a$ concepção é .... Ainda assim, é preciso alinhavar algo sobre as compreensões que fomos juntando ao longo desta nossa investigação.

Iniciamos esta pesquisa pensando em analisar as práticas sobre Ensino e Aprendizagem da Matemática de Professores dos Anos Iniciais do Estado de Santa Catarina tendo as Feiras Catarinenses de Matemática como cenário, posto que esses eventos promovem, especificamente, a divulgação de práticas alternativas para o ensino de 
Matemática. Desde o início, por isso, pensamos em ter como colaboradores professores que tivessem uma prática destacada ou diferenciada em relação ao ensino dessa disciplina, por mais complexa que fosse a caracterização do que seria uma boa prática ou uma prática destacada, diferenciada. A opção pelas Feiras de Matemática respondia a esse quesito sem, necessariamente, estabelecer um significado padrão do que fossem essas práticas que buscávamos. Sob algum critério, uma certa comunidade, organizadamente, atribuía a marca da diferenciação a algumas experiências vividas por professores e alunos em suas salas de aula.

O fato de acreditarmos que não é meramente a formação que faz o professor ser o profissional que ele é hoje, mas sim que ele se torna o que é devido a um acumulado de experiências vividas por ele ao longo de sua vida, nos levou a buscar apoio na Metodologia de Pesquisa conhecida por História Oral, posto que ela tem se mostrado um modo adequado, legítimo e eficaz de auscultar as nuances subjetivas de certas situações, vividas e comunicadas por aqueles que as experienciaram. A História Oral não é, certamente, a única metodologia possível para um trabalho como o que nos propusemos a realizar, mas ter, como apoio, nessa nossa trajetória, o conjunto das investigações realizadas pelo $\mathrm{GHOEM}^{16}$, grupo de pesquisa do qual fazemos parte, reforçou significativamente nossas intenções e subsidiou, de modo definitivo, essa nossa opção pelo método.

As Feiras Catarinenses de Matemática formam como que um pano de fundo para nossa pesquisa. Em primeira instância, essas Feiras seriam o lugar onde procuraríamos nossos colaboradores. Essa escolha foi baseada no fato de esse lugar ser um evento educacional de grande porte no estado com o qual os pesquisadores já haviam se envolvido. Definidos os critérios de seleção, fomos à busca dos possíveis colaboradores entre os professores que participaram das vinte e cinco primeiras edições do evento. Quinze professoras, residentes e atuantes em diferentes cidades do estado de Santa Catarina, aceitaram nosso convite. As narrativas dessas professoras tratam de seus cotidianos em sala de aula, suas perspectivas em relação à Matemática e seu ensino, seus desejos, dificuldades, sucessos e fracassos na docência e, como docentes, de suas perspectivas, sucessos e fracassos em relação à Matemática, sendo elas professoras que também ensinam essa disciplina, entre os tantos objetos de que cuidam em suas salas de aula. Essas narrativas passaram a ser, como já pressupúnhamos, peças-chave do quebra-cabeça que pretendíamos esboçar. Esboçar, aqui, é um verbo mais pertinente que montar, pois, segundo nossa perspectiva, nem nossa questão -

\footnotetext{
${ }^{16}$ Grupo de Pesquisa "História Oral e Educação Matemática”: www.ghoem.org
} 
sobre as concepções - nem nossa metodologia - a História Oral - se prestariam a resultados objetivos, como as paisagens completas que surgem aos nossos olhos quando as inúmeras peças de um jogo estão dispostas sobre a mesa. Cada uma de nossas peças são singulares e mutáveis, que só se dão ao pesquisador à luz dos significados que ele - pesquisador - atribui a elas, e é nessas singularidades atribuídas que cada uma dessas peças deveria ser compreendida, fazendo algum sentido na totalidade do jogo que nos propusemos jogar, no conjunto das peças que nos propusemos montar.

Entre essas peças, cada vez mais, na trajetória da pesquisa, as Feiras de Matemática se mostravam como peça importante, bem mais importante e presente, digamos, do que havíamos pensado ser no início do trabalho. As Feiras não seriam, portanto, mero pano de fundo da investigação, mas pano de frente, cenário centralizado, tamanha a importância que, segundo nossos olhos, percebíamos terem elas tido na formação das professoras colaboradoras.

As possibilidades de analisar cada uma das narrativas - para, em seguida, tentar uma análise em bloco das narrativas - se mostraram vastas: cada elemento percebido, cada significado por nós atribuído modificava o formato das peças, alterando perspectivas que tínhamos do jogo e da ação de jogar. Devido ao tempo de que dispusemos, fizemos nossas opções, e uma síntese do panorama esboçado é o que pode ser lido neste artigo. Se não há um modo de caracterizar as concepções das professoras de Matemática sobre o ensino e a aprendizagem dessa disciplina, podemos aventar que essas perspectivas passam pelas dificuldades e sucessos vivenciados durante suas formações; pela lacunaridade das disciplinas específicas sobre o tema em cursos de Magistério e de Pedagogia; pelos lugares comuns que se manifestam nas tentativas de comunicar o que, segundo cada uma delas, a Matemática é; pelos esforços implementados por cada uma dessas professoras para ultrapassar suas lacunas de aprendizado e suas deficiências em relação à Matemática; pela reedição de discursos como aquele frequentemente atribuído à Escola Nova ou as atuais políticas educacionais - há muito em voga na literatura educacional; e à tentação de caracterizar o ensino de Matemática adequado meramente como aquele plasmado em preocupações relativas ao contexto do aluno e aos materiais manipulativos e jogos didáticos. Essas e muitas outras características se insinuam - às vezes mais, às vezes menos claramente - no conjunto de narrativas que estudamos. Ressalta-se, também, a perspectiva das Feiras como uma tentativa de vencer alguns obstáculos relativos ao ensino e à aprendizagem de Matemática, mas uma tentativa que também tropeça ao criar e eliminar regras que claramente apontam a dificuldade em avaliar 
comprometimentos e práticas alternativas de ensino, mas que, ao mesmo tempo, se mostra como um lugar praticado - e visto como fundamental - pela comunidade à qual as Feiras se dirigem.

\section{Referências}

BRASIL. Ministério da Educação. Diretrizes Operacionais para Educação Básica nas Escolas do Campo do Governo Federal. Parecer n ${ }^{0} 36 / 2001$; Conselho Nacional de Educação, aprovado em 04/12/2001. Disponível em:

<http://portal.mec.gov.br/cne/arquivos/pdf/EducCampo01.pdf.>. Acesso em: 15 fev. 2013>. Acesso em 25 mai. 2013.

BRASIL. Secretaria de Educação Fundamental. Parâmetros Curriculares Nacionais: Matemática. Brasília: MEC/SEF, 1997. 142 p.

CURI, E. A Matemática e os Professores dos Anos Iniciais. São Paulo: Musa, 2005. 175 p.

FLORIANI, J. V.; ZERMIANI, V. J. Feira de Matemática. Revista de Divulgação

Cultural, Blumenau, v. 8, n. 28, p.1-16, dez. 1985.

FLORIANI, J.V.; ZERMIANI, V.J. Trajetória da Rede de Feiras de Matemática. In: IV SEMINÁRIO SOBRE FEIRAS DE MATEMÁTICA, 4, 2009, Blumenau. Anais... Blumenau: Nova Letra, 2009. v. 1, p. 37 - 44.

GAERTNER, R. A Matemática Escolar em Blumenau (SC) no período de 1889 a 1968: da Neue Deutsche Schule à Fundação Universidade Regional de Blumenau. 2004. 248 f. Tese (Doutorado em Educação Matemática) - Instituto de Geociências e Ciências Exatas, Universidade Estadual Paulista, Rio Claro, 2004.

MARTINS, M. E. Resgate Histórico da Formação e Atuação de Professores da Escola Rural: um estudo no oeste paulista. 2003. 261f. Relatório Final de pesquisa de Iniciação Científica, FAPESP Fundação de amparo à Pesquisa do Estado de São Paulo, UNESP: Bauru, 2003.

MARTINS-SALANDIM, M. E. Uma Cartografia da Formação de Professores que ensinam Matemática: o interior do Estado de São Paulo na década de 1960. In: FERREIRA, A. C.; BRITO, A. J.; MIORIM, M .A. (Org.). Histórias de Formação de Professores que Ensinaram Matemática no Brasil. Campinas: Ílion, 2012. p. 137-154.

NACARATO, A. M.; MENGALI, B. L. S.; PASSOS, C. L. B. A Matemática nos Anos Iniciais do Ensino Fundamental. Belo Horizonte: Autêntica, 2009. 158 p.

PASSOS, C. L. B.; ROMANATTO, M. C. A Matemática na formação de Professores dos Anos Iniciais: aspectos teóricos e metodológicos. São Carlos: EdUFSCar, 2010. 107 p.

SILVA. V. C. Narrativas de Professoras que ensinam Matemática na Região de Blumenau (SC): sobre as Feiras Catarinenses de Matemática e as práticas e concepções sobre ensino e aprendizagem de matemática. 2014. 321f. Tese (Doutorado em Educação para a Ciência) Faculdade de Ciências, Universidade Estadual Paulista, Bauru, 2014.

ZERMIANI, V. J. (Org.). In: SEMINÁRIO DE AVALIAÇÃO DAS FEIRAS CATARINENSES DE MATEMÁTICA, 2, 2002, Blumenau. Anais... Blumenau: Edifurb, 2002. 156p. 
ZERMIANI, V. J. Feiras de Matemática de Santa Catarina: relevância para a educação. Blumenau: Edifurb, 2003. 141 p.

ZERMIANI, Vilmar José (Org.). In: SEMINÁRIO SOBRE FEIRAS DE MATEMÁTICA, 4, 2009, Blumenau. Anais... Blumenau: Nova Letra, 2009. 253p.

ZERMIANI, Vilmar José (Org.). In: REGIMENTO DA XXIX FEIRA CATARINENSE DE

MATEMÁTICA, 2013. 18p. Disponível em: http://proxy.furb.br/files/Regimento.pdf. Acesso em 02 mai 2014.

Submetido em Abril de 2015. Aprovado em Junho de 2015. 